\title{
A PESCA EXTRATIVA MARINHA NO PORTO DE ATAFONA, SÃO JOÃO DA BARRA - RJ: PASSADO E PRESENTE
}

\author{
BONFIM, B.C. ${ }^{1}$; SANTOS, A.F.G.N. ${ }^{1,2}$ \& DI BENEDITTO, A.P. ${ }^{3}$
}

\author{
1. Programa de Pós- Graduação em Biotecnologia Marinha IEAPM/UFF, Arraial do Cabo - RJ, Brasil. \\ 2. Laboratorio de Ecologia Aplicada, Dept. Zootecnia e Desenvolvimento Agrossocioambiental \\ Sustentável, Faculdade de Veterinária, Universidade Federal Fluminense (UFF), Niterói - RJ, Brasil. \\ 3. Laboratório de Ciências Ambientais, Centro de Biociências e Biotecnologia, Universidade Estadual \\ do Norte Fluminense (UENF), Campos dos Goytacazes - RJ, Brasil. \\ *Corresponding author: brunocarvalhobonfim@hotmail.com
}

\begin{abstract}
Bonfim, B.C.; Santos, A.F.G.N. \& Di Beneditto, A.P., 2017. A pesca extrativa marinha no porto de Atafona, São João da Barra - RJ: passado e presente. Braz. J. Aquat. Sci. Technol. 21(1). elSSN 1983-9057. DOI: 10.14210/bjast. v21n1. This study aims to compare the current information on artisanal fishery practised in Atafona harbour, São João da Barra, RJ, with the artisanal fishery practised in this region 15 years ago. Currently, there are 133 boats operating with the following fishing gears: a) fishing nets - trawl net, purse seine net and gill net and b) fishing lines - handline and longline. According to the fishermen, the local fishery is affected by the increase in fishing effort, reduction in captures, changes in the preferred fishing grounds, fishing costs increase and competition with boats from other sites. The main changes in the local fishery were increase in fishing technology and fishing capacity of boats, changes in fishing gears, in mesh size of the gill nets and in the preferred fishing grounds. Fishery management measures should be undertaken to ensure the maintenance of local stocks in viable levels for exploitation, minimizing the fishery impacts.
\end{abstract}

Key Words: Fishing gears, Fisheries management, Temporality, Northern Rio de Janeiro state.

\section{INTRODUÇÃO}

A pesca é uma das atividades mais antigas praticadas pelo homem para obtenção de recursos alimentares (ABDALLAH e CASTELLO, 2003). Os recursos pesqueiros representam importante fonte alimentar para as populações humanas, movimentando a economia do Brasil e de outros países (ABDALLAH e CASTELLO, 2003; MPA, 2014; FAO, 2016).

No Brasil, estima-se que a pesca extrativa marinha seja responsável por cerca de $57 \%$ da produção pesqueira, com os outros $42 \%$ oriundos de atividades de aquicultura. A pesca industrial representa apenas $20 \%$ dos desembarques pesqueiros enquanto a pesca artesanal totaliza $80 \%$ da produção nacional (SILVA, 2014). Dentre os principais alvos da pesca marinha em águas jurisdicionais brasileiras estão os peixes: sardinha Sardinella brasiliensis, corvina Micropogonias furnieri, pescada amarela Cynoscion acoupa, bonito listrado Katsuwonus pelamis; e os crustáceos: camarão sete barbas Xiphopenaeus kroyeri e o camarão rosa Farfantepenaeus spp (MPA, 2011).

Não há um consenso sobre o significado do termo pesca artesanal ou de pequena escala. Por definição, esse tipo de atividade é oposto à pesca industrial ou de larga escala que utiliza tecnologias sofisticadas e envolve elevados investimentos que não são acessíveis as comunidades pesqueiras (SILVA, 2014). Na pesca artesanal, os pescadores trabalham sozinhos ou utilizam mão-de-obra familiar ou de demais membros da comunidade, explorando geralmente os ambientes localizados próximos à costa (CLAUZET et al., 2005; MPA, 2014). A pesca artesanal é caracterizada como uma atividade praticada para fins de subsistência ou comercialização em pequena escala. Os pescadores atuam tanto de forma desembarcada quanto por meio de embarcação com arqueação bruta menor ou igual a 20 toneladas (BRASIL, 2009 - LEI 11.959/09; BRASIL, 2011 - INSTRUÇÃO NORMATIVA 2 de 25 de janeiro 2011).

Segundo dados da Fundação Instituto de Pesca do Estado do Rio de Janeiro - FIPERJ (FIPERJ, 2015), o estado é o terceiro produtor de pescado do Brasil com cerca de 79 mil toneladas em 2015, possui linha de costa com $635 \mathrm{~km}$ de extensão e 27 municípios costeiros, destacando-se Angra dos Reis, Niterói, São Gonçalo, Cabo Frio e São João da Barra como os principais produtores. As principais espéciesalvo de pescado do estado são: sardinha, cavalinha (Scombridae spp), bonito listrado, savelha (Brevoortia aurea) e xerelete (Caranx latus) (FIPERJ, 2015).

O porto de Atafona se localiza no município de São João da Barra, costa norte do estado do Rio de Janeiro. A pesca praticada a partir desse porto apresenta todas as características indicadas acima e, por isso, é caracterizada como artesanal. A pesca é a principal atividade econômica na região, envolvendo homens e mulheres de modo direto ou indireto, com os homens atuando na pesca e as mulheres no beneficiamento do pescado e no reparo dos artefatos de 
pesca (FALCÃO, 2013). Os levantamentos específicos sobre a prática pesqueira neste porto foram realizados há mais de 15 anos, indicando 145 embarcações com comprimentos entre 7-12 m, capacidade de carga de 0,8-6,4 toneladas e 600 pescadores em atividade (DI BENEDITTO et al., 1998; DI BENEDITTO, 2001). De acordo com esses levantamentos, as principais modalidades de pesca utilizadas pelos pescadores eram redes de arrasto, redes de espera e vários tipos de linha. As espécies alvo com maior destaque eram peroá Balistes spp (56 tonelanas/ano), corvina (176 toneladas/ano), cações Carcharhinus plumbeus e Rhizoprionodon porosus (176 toneladas/ano) e camarão sete barbas (828 toneladas/ano).

O cenário pesqueiro regional é influenciado pela exploração de petróleo realizada na Bacia de Campos desde a década de 1970 e pela erosão e consequente avanço do mar no litoral de Atafona desde a década de 1960, que modifica a estrutura morfológica da linha de costa (FERNANDEZ et al., 2006; FALCÃO, 2013). Adicionalmente, desde 2009 a área costeira do município de São João da Barra tem se modificado devido à instalação do mega-empreendimento Complexo Logístico Industrial e Portuário do Açu (CLIPA). Os impactos gerados pelas atividades do CLIPA, tais como alteração morfológica da costa, redução da diversidade de espécies e poluição química e por rejeitos sólidos estão modificando a dinâmica marinha na área do entorno do empreendimento, afetando diretamente a pesca regional (SOUZA e OLIVEIRA, 2010; OLIVEIRA et al., 2016; ZAPPES et al., 2016).

Diante do exposto, o presente estudo tem como objetivo comparar as informações atuais sobre a pesca extrativa marinha no porto de Atafona com a pesca na região há 15 anos, de forma a avaliar as alterações temporais na atividade e dimensionar procedimentos mitigadores dos problemas da pesca regional.

\section{MATERIAIS E MÉTODOS}

\section{Área de estudo}

O porto de Atafona $\left(21^{\circ} 35^{\prime} \mathrm{S}\right.$; $\left.041^{\circ} 03^{\prime} \mathrm{W}\right)$ se localiza na margem direita da foz principal do rio Paraíba do Sul (Figura 1). Este porto é o principal ponto de atracadouro e desembarque pesqueiro marinho desta região, reunindo embarcações vinculadas principalmente à pesca extrativa marinha praticada em águas costeiras. Os pescadores que atuam a partir desse porto estão vinculados a Colônia de Pescadores Z-02.

\section{Levantamento de dados}

A atualização das informações sobre a pesca artesanal praticada a partir do porto de Atafona foi realizada em 2014 através de entrevistas com aplicação de questionários semiestruturados aos pescadores locais (um pescador por embarcação), considerando as modalidades de pesca praticadas. Optou-se pela amostragem de $20 \%$ do total de embarcações em operação como representativa da pesca local. Percentual semelhante foi utilizado por FERNANDES et al. (2014) para avaliação de pesca de camarões realizada no mesmo porto, com resultados satisfatórios.

Para a seleção dos entrevistados foram estabelecidos os seguintes critérios: (1) ser pescador artesanal, (2) ter a pesca como principal atividade econômica e (3) praticar a pesca artesanal a partir do porto de Atafona desde o ano 2000, pelo menos. O último critério se refere a experiência do pescador na região, com maior possibilidade de perceber as eventuais mudanças temporais no cenário da atividade pesqueira local. Todos os pescadores foram entrevistados individualmente para evitar a interferência do relato de um pescador sobre o outro. As entrevistas foram conduzidas no porto, após o desembarque pesqueiro, por um único entrevistador (B.C. Bonfim). O mesmo questionário foi aplicado a todos os entrevistados. As questões abordadas no questionário eram referidas a: i) características da embarcação, ii) número de tripulantes, iii) características do artefato de pesca utilizado, iv) modo de operação do artefato
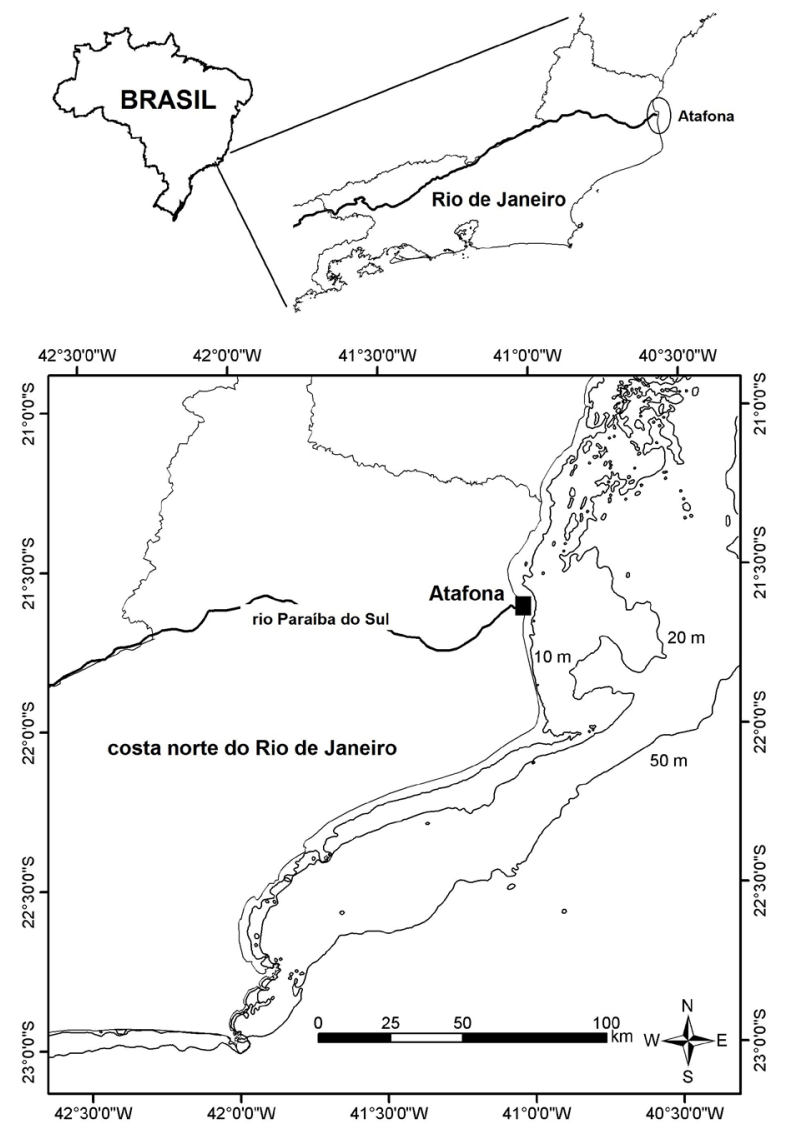

Figura 1 - Localização do porto de Atafona no município de São João da Barra, costa norte do estado do Rio de Janeiro, sudeste do Brasil. 
e v) principais espécies-alvo. Adicionalmente, a cada entrevistado foi perguntado se sentiu alguma mudança na atividade pesqueira nos últimos anos e qual seria o possível motivo dessa mudança. Os entrevistados poderiam indicar mais de um motivo se a resposta a primeira questão fosse sim (houve mudança na atividade pesqueira).

Para os dados pretéritos foram utilizados os resultados obtidos em estudos conduzidos por DI BENEDITTO et al. (1998) e DI BENEDITTO (2001). Os dados pretéritos foram comparados com os dados atuais com o intuito de identificar as principais mudanças ocorridas na atividade pesqueira em Atafona nos últimos 15 anos. Aplicou-se o cálculo do coeficiente de variação (CV) para testar as diferenças de variação entre os dados pretéritos e os dados do presente estudo através do programa Statistic 8 .

\section{RESULTADOS}

\section{Características da pesca regional}

Foram amostrados $20 \%(n=27)$ do total de embarcações em atuação no porto de Atafona ( $n=$ 133) (Tabela 1). Todas as embarcações apresentam casco de madeira, casaria e motor a diesel. Estimase que aproximadamente 600 pescadores estão em atividade neste porto, todos do sexo masculino. A estrutura pesqueira local inclui 3 fábricas de gelo, 11 entrepostos de desembarque (ou frigoríficos) e 2 postos de abastecimento de óleo diesel.
Tabela 1 - Quantificação das modalidades de pesca praticadas pelas embarcações em atividade no porto de Atafona, município de São João da Barra/RJ, em 2014.

\begin{tabular}{lcc}
\hline Modalidade de pesca (nome popular local) & $\mathrm{N}^{\circ}$ embarcações & $\%$ \\
\hline Rede de arrasto de fundo (camarão) & 34 & 25,6 \\
Rede de arrasto rebocado por duas embarcações (parelha) & 02 & 1,5 \\
Rede de traineira (cerco) & 08 & 6,0 \\
Rede de espera (pescadinha) & 07 & 5,3 \\
Rede de espera (minjuada) & 10 & 7,5 \\
Rede de espera (caída) & 32 & 24,0 \\
Linha - linha de mão (pargueira) & 23 & 17,3 \\
Linha - Espinhel & 17 & 12,8 \\
Total & $\mathbf{1 3 3}$ & $\mathbf{1 0 0 , 0}$ \\
\hline
\end{tabular}

As artes de pesca praticadas estão incluídas nas divisões de rede e linha, segundo classificação do CEPSUL (2014). Na divisão de rede são registrados os seguintes artefatos de pesca: i) rede de arrasto (arrasto de fundo e parelha), ii) rede de traineira ou cerco e iii) rede de espera ou emalhe (pescadinha, minjuada e caída). Na divisão de linha são registradas: i) linha de mão (pargueira) e ii) espinhel (Tabela 1). A maioria das embarcações em atividade $(69,9 \%)$ utiliza a rede como principal artefato de pesca. A rede mais utilizada é a rede de emalhe $(36,8 \%)$, seguida da rede de arrasto de fundo $(27,1 \%)$ e da rede de traineira $(6 \%)$. Dentre as redes de emalhe, a caída é a mais utilizada pelas embarcações atualmente (24\%) (Tabela 1). Já as embarcações que utilizam linhas como artefatos totalizaram $30,1 \%$ do total de embarcações, com a maioria utilizando a linha de mão pargueira $(17,3 \%)$ seguida do espinhel (12,8\%) (Tabela 1).

As descrições dos artefatos de pesca, incluindo as características das embarcações que os utilizam,

Tabela 2 - Caracterização dos artefatos de pesca utilizados no porto de Atafona, município de São João da Barra/RJ.

\begin{tabular}{|c|c|c|c|c|c|c|}
\hline Artefatos de pesca & $\begin{array}{l}\text { Rede de arrasto de } \\
\text { fundo }\end{array}$ & Rede de parelha & Rede de traineira (cerco) & $\begin{array}{c}\text { Redes de emalhe (espera) } \\
\text { - pescadinha, minjuada, } \\
\text { caída }\end{array}$ & $\begin{array}{l}\text { Linha de mão } \\
\text { (pargueira) }\end{array}$ & Espinhel \\
\hline Tripulação & $2-3$ pescadores & 5 pescadores & $8-9$ pescadores & 2-4 pescadores & $2-3$ pescadores & 5 pescadores \\
\hline Embarcação & $\begin{array}{l}9-10,5 \text { m comprimento; } 2,4- \\
3,5 \mathrm{~m} \text { largura; } 2-6 \text { ton carga; } \\
15-90 \text { HP potência do motor }\end{array}$ & $\begin{array}{l}10,5-11 \text { m comprimento; } 2,8- \\
3 \mathrm{~m} \text { largura; } 3 \text { ton carga; } 60 \\
\text { HP potência do motor }\end{array}$ & $\begin{array}{l}12,8-13,4 \mathrm{~m} \text { comprimento; } \\
3,9-5 \mathrm{~m} \text { largura; } 12-13,5 \text { ton } \\
\text { carg; } 30-160 \mathrm{HP} \text { potência do } \\
\text { motor }\end{array}$ & $\begin{array}{l}\text { 9,5-13,6 m comprimento; } 2,5-4 \\
\text { m largura; } 2-12 \text { ton carga; } 30- \\
90 \text { HP potência do motor }\end{array}$ & $\begin{array}{l}\text { 9-11 m comprimento; } \\
2,5-4,5 \mathrm{~m} \text { largura; } 2-5 \\
\text { ton carga; } 30-60 \mathrm{HP} \\
\text { potência do motor }\end{array}$ & $\begin{array}{l}\text { 13-13,3 m comprimento; } \\
\text { 3-4,3 m largura; } 10-11 \\
\text { ton carga; } 60-90 \text { HP } \\
\text { potência do motor }\end{array}$ \\
\hline $\begin{array}{l}\text { Equipamentos de } \\
\text { bordo }\end{array}$ & $\begin{array}{lr}\text { Rádio-comunicação; } & \text { GPS; } \\
\text { ecossonda; } & \text { guincho } \\
\text { motorizado ror } & \text { para } \\
\text { recolhimento da rede } & \end{array}$ & $\begin{array}{ll}\text { Rádio-comunicação; } & \text { GPS; } \\
\text { guincho motorizado } & \text { para } \\
\text { recolhimento da rede } & \end{array}$ & $\begin{array}{lr}\text { Rádio-comunicação; } & \text { GPS; } \\
\text { ecossonda; } & \text { guincho } \\
\text { motorizado dara } & \text { para } \\
\text { recolhimento da rede } & \end{array}$ & $\begin{array}{ll}\text { Rádio-comunicação; } & \text { GPS; } \\
\text { guincho motorizado } & \text { para } \\
\text { recolhimento da } & \text { rede } \\
\text { (minguada e caída) } & \end{array}$ & $\begin{array}{l}\text { Rádio-comunicação; } \\
\text { GPS; ecossonda }\end{array}$ & $\begin{array}{l}\text { Rádio-comunicação; } \\
\text { GPS; ecossonda }\end{array}$ \\
\hline Dimensões do artefato & $\begin{array}{l}2 \text { redes cônicas; } 6-22 \mathrm{~m} \\
\text { comprimento; } 2-8 \mathrm{~m} \text { largura } \\
\text { da boca; } 15-20 \mathrm{~mm} \text { malha } \\
\text { no corpo e } 13-15 \mathrm{~mm} \text { malha } \\
\text { no ensacador; } 2 \text { portas de } \\
\text { madeira } 20-30 \mathrm{~kg}\end{array}$ & $\begin{array}{l}27 \mathrm{~m} \text { comprimento; } 10 \mathrm{~m} \\
\text { altura; } 35 \mathrm{~mm} \text { malha; } \\
\text { cortiças na parte superior e } \\
\text { corrente de ferro } 12 \mathrm{~kg} \text { na } \\
\text { parte inferior }\end{array}$ & $\begin{array}{l}5700-6000 \mathrm{~m} \text { comprimento; } \\
54-61 \mathrm{~m} \text { altura; } 20-25 \mathrm{~mm} \\
\text { malha; cortiças na parte } \\
\text { superior e chumbos na parte } \\
\text { inferior }\end{array}$ & 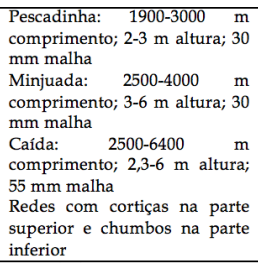 & $\begin{array}{l}\text { Linha principal } \\
\text { (comprimento } \\
\text { depende } \\
\text { profundidade da } \\
\text { campo de pesca) e } \\
\text { linhas secundárias } \\
\text { com anzós }\left(\mathrm{n}^{\circ} 12 \text { e }\right. \\
\text { 13); prumo } 1,3 \mathrm{~kg}\end{array}$ & $\begin{array}{l}\text { Linha principal (8000- } \\
11300 \mathrm{~m} \text { comprimento) } \mathrm{e} \\
\text { linhas secundárias }(800- \\
1200 \text { linhas com } 3,6-4,5 \\
\mathrm{~m} \text { comprimento }) \text { com } \\
\text { anzol }(127 \mathrm{~mm})\end{array}$ \\
\hline $\begin{array}{l}\text { Modo de operação do } \\
\text { artefato }\end{array}$ & $\begin{array}{lr}\text { Redes rebocadas } & \text { pela } \\
\text { embarcaçāo; } & 4-8 \\
\text { lançamentos/dia; } & 1-2 \\
\text { h/arrasto; } 6 \text { dias/semana }\end{array}$ & $\begin{array}{lll}\text { Rede rebocada por } & 2 \\
\text { embarcaçös; } & & 2 \\
\text { lançamentos/dia; } & & 4 \\
\text { h/arrasto; 6 dias/semana } & \end{array}$ & $\begin{array}{lr}2-4 \quad \text { lançamentos/dia; } & \mathbf{2} \\
\mathrm{h} / \text { cerco; } 3 \text { dias/semana }\end{array}$ & $\begin{array}{ll}\text { Pescadinha: } & 2-3 \\
\text { lançamentos/dia; } & 3-4 \\
\text { h/imersão; } 4-5 \text { dias/semana } \\
\text { Minjuada: 2 lançamentos/dia; } \\
\text { 8-20 h/imersão; } 5-6 \\
\text { dias/semana } \\
\text { Caída: 1-2 lançamentos/dia; } \\
\text { 10-12 h/imersāo; 5-7 } \\
\text { dias/semana } \\
\end{array}$ & $\begin{array}{l}\text { Prumo direciona linha } \\
\text { verticalmenter ao } \\
\text { fundo; camarăo usado } \\
\text { como isca; dezenas de } \\
\text { lançamentos/dia com } \\
\text { duraçāo variável; } 4-6 \\
\text { dias/semana }\end{array}$ & $\begin{array}{l}\text { Linha posicionada } \\
\text { horizontalmente na água } \\
\text { com âncoras nas } \\
\text { extremidades; cavalinha, } \\
\text { sardinha, lula e bonito } \\
\text { listrado usados como } \\
\text { isca; } 2 \text { lanşamentos/dia; } \\
\text { 8-12 h/imersāo; 8-15 } \\
\text { dias/consecutivos }\end{array}$ \\
\hline $\begin{array}{l}\text { Pesqueiros } \\
\text { preferenciais }\end{array}$ & $\begin{array}{l}\text { Foz rio Paraíba do Sul e } \\
\text { litoral de São João da Barra, } \\
\text { até } 3 \text { milhas da costa }\end{array}$ & $\begin{array}{l}\text { Foz rio Paraíba do Sul e } \\
\text { litoral de São João da Barra }\end{array}$ & $\begin{array}{l}\text { Bacia de Campos, em } \\
\text { profundidade média de } 30 \\
\mathrm{~m}\end{array}$ & $\begin{array}{l}\text { Aguas costeiras da Bacia de } \\
\text { Campos }\end{array}$ & $\begin{array}{l}\text { Bacia de Campos, } \\
\text { águas costeiras até } 36 \\
\text { milhas da costa }\end{array}$ & Bacia de Campos \\
\hline Espécies alvo & Camarāo sete barbas & Pescadas e pescadinhas & $\begin{array}{l}\text { Xerelete, anchova, sarda, } \\
\text { bonito listrado e } \\
\text { pintado }\end{array}$ & $\begin{array}{l}\text { Corvina, pescadas, anchova, } \\
\text { sarda, cações }\end{array}$ & $\begin{array}{l}\text { Peró́ leste, baiacu e } \\
\text { roncador }\end{array}$ & $\begin{array}{l}\text { Anchova, olho-de-boi, } \\
\text { dourado }\end{array}$ \\
\hline
\end{tabular}


suas dimensões, modo de operação, pesqueiros e espécies-alvo preferenciais estão indicados na Tabela 2.

\section{Mudanças na pesca regional - percepção dos pescadores e variação temporal}

O aumento no esforço de pesca e a redução dos estoques pesqueiros regionais foram mencionados com maior frequência como os principais fatores que afetam a atividade pesqueira na região. Muitos entrevistados indicaram de forma espontânea mais de um fator, o que explica o número de respostas ter sido maior que o número total de entrevistados ( $\mathrm{n}=$ 27) (Tabela 3).

Tabela 3 - Principais fatores que afetam a pesca extrativa marinha praticada no porto de Atafona, município de São João da Barra/RJ. $\mathrm{N}=$ numero amostral.

\begin{tabular}{lcc}
\hline Fatores que afetam a pesca & N & $\%$ \\
\hline Aumento do esforço de pesca & 12 & 41 \\
Redução dos estoques pesqueiros & 10 & 34 \\
Alteração nos pesqueiros preferenciais & 8 & 31 \\
Aumento dos gastos nas operações de pesca & 6 & 20 \\
Concorrência com embarcações de outras regiões/portos & 4 & 13 \\
\hline
\end{tabular}

Comparando o resultado do atual estudo com os resultados dos estudos pretéritos, houve redução no número de embarcações em atividade, passando de 145 para 133 embarcações. O número estimado de pescadores em atividade se manteve igual, com aproximadamente 600 pescadores. Houve mudança também na capacidade de carga das embarcações, que passaram de 6,4 toneladas para 13 toneladas nos dias de hoje. O comprimento das embarcações também sofreu mudanças ao longo dos anos, passando de 7-12 metros para 9-13 metros. A infraestrutura local de apoio a pesca não se modificou de modo expressivo, mantendo o mesmo número de fábricas de gelo, mas com leve incremento no número de pontos de desembarque (9 para 11). Considerando as redes de emalhe que são utilizadas pelas embarcações sediadas no porto de Atafona, verifica-se que o comprimento sofreu aumento expressivo, e hoje é $50 \%$ a $270 \%$ maior que há 15 anos (Tabela 4).

Tabela 4. Variação temporal das características da pesca extrativa marinha praticada no porto de Atafona, município de São João da Barra/RJ. *DI BENEDITTO et al. (1998) e DI BENEDITTO, (2001). $\mathrm{CV}=$ coeficiente de variação.

\begin{tabular}{lccc}
\hline Características & $1998-2001^{*}$ & 2014 & CV \\
\hline Embarcações em atividade & 145 & 133 & 6,1 \\
Pescadores em atividade & $\sim 600$ & $\sim 600$ & 0 \\
Comprimento médio das embarcações (m) & 9,5 & 11 & 10,3 \\
Capacidade média de carga (toneladas) & 3,6 & 7,5 & 49,7 \\
Fábricas de gelo & 3 & 3 & 0 \\
Pontos de desembarque & 9 & 11 & 14,1 \\
Comprimento médio das redes de emalhe $(\mathrm{km})$ & 3,7 & 4,2 & 8,9 \\
\hline
\end{tabular}

Ao se comparar a forma de realização da pesca extrativa marinha regional ao longo dos anos também se notam variações nas modalidades de pesca preferenciais, com inversão na representatividade das modalidades de rede de arrasto de fundo e de linha (Tabela 5). A rede de arrasto de fundo representava $45 \%$ do total das embarcações em atividade, e atualmente a modalidade representa $25,6 \%$ do total de embarcações. As embarcações que utilizam modalidades de pesca de linha ganharam mais representatividade, passando de $12 \%$ para $30,1 \%$ no atual estudo (Tabela 5).

Tabela 5. Distribuição percentual e variação temporal das principais modalidades de pesca praticadas no porto de Atafona, município de São João da Barra/RJ. *DI BENEDITTO et al. (1998) e DI BENEDITTO, (2001). CV= coeficiente de variação.

\begin{tabular}{lccc}
\hline Modalidades de pesca & $1998-2001^{*}$ & 2014 & $\mathrm{CV}$ \\
\hline Rede de arrasto de fundo & 45,0 & 25,6 & 38,8 \\
Redes de emalhe e traineira & 43,0 & 44,3 & 2,1 \\
Linhas & 12,0 & 30,1 & 60,8 \\
\hline
\end{tabular}

Outra mudança verificada se refere ao tamanho da malha das redes de emalhe utilizadas em Atafona. A rede conhecida como pescadinha manteve o tamanho da malha na comparação entre os estudos. Já as redes de minjuada e caída sofreram uma redução significativa de $50 \%$ e $26 \%$ no tamanho da malha, respectivamente (Tabela 6 ).

Tabela 6 - Variação temporal no tamanho da malha (medida entre nós adjacentes) das redes de emalhe utilizadas no porto de Atafona, município de São João da Barra/RJ. *DI BENEDITTO et al. (1998) e DI BENEDITTO (2001). CV= coeficiente de variação.

\begin{tabular}{lccc}
\hline Redes de emalhe & $1998-2001^{*}$ & 2014 & CV \\
\hline Pescadinha & 30 & 30 & 0 \\
Minjuada & 60 & 30 & 47,1 \\
Caída & 70 & 55 & 16,9 \\
\hline
\end{tabular}

\section{DISCUSSÃO}

A pesca artesanal praticada a partir do porto de Atafona é uma importante atividade econômica para o município de São João da Barra, gerando emprego e renda para parte da população local. Comparandose os dados levantados pelo presente estudo com as informações de DI BENEDITTO et al. (1998) e DI BENEDITTO (2001) verifica-se que o número de pescadores que atuam a partir desse porto se mantém constante ao longo dos anos, indicando que o vínculo com a atividade permanece de uma geração para outra ou que os pescadores se mantêm mais tempo exercendo esta atividade profissional.

FERNANDES et al. (2014) indicaram em seu estudo que o ingresso dos descendentes de pescadores na atividade pesqueira local voltada para captura do camarão sete barbas diminuiu, demonstrando que esse ingresso já não ocorre mais precocemente (infân- 
cia ou adolescência). A crise ambiental e econômica que afeta a pesca no Brasil tem provocado nos jovens filhos de pescadores a falta de interesse e abandono da atividade pesqueira. Com o crescimento de outras atividades, como turismo e empreendimentos próximos a áreas litorâneas, os jovens procuram outras áreas econômicas para atuar, buscando estabilidade monetária e direitos trabalhistas. Esse cenário é registrado na região estudada a partir da implantação do CLIPA (ZAPPES et al., 2016). Os pescadores mais veIhos também buscam outras atividades remuneradas para complementar a renda familiar (CAPELLESCO e CAZELLA, 2011; FERNANDES et al., 2014).

Apesar do número de embarcações em operação no porto de Atafona ter diminuído cerca de $8 \%$ neste intervalo de tempo ( 15 anos), a sua capacidade operacional, incluindo comprimento e capacidade de carga aumentou (Tabela 3). Isso provavelmente permitiu que o mesmo número de pescadores estivesse agora distribuído em um menor número de embarcações. Adicionalmente, as tecnologias pesqueiras que atualmente fazem parte da estrutura operacional das embarcações não eram utilizadas há alguns anos na região (DI BENEDITTO, 2001). Os recursos tecnológicos aumentam a segurança durante a navegação (radiocomunicação, GPS), facilitam a localização das espécies alvo (ecossonda) e o manejo dos artefatos de pesca (guincho mecanizado), conferindo maior autonomia de pesca e ampliando a possibilidade de exploração de áreas mais afastadas da linha de costa ou do porto de desembarque principal (Atafona).

No entanto, o aumento da capacidade operacional e a utilização de tecnologias podem não estar necessariamente se refletindo em aumento da produção pesqueira local. Isso é expresso pelas características do escoamento desta produção, a partir da manutenção da mesma quantidade de fábricas de gelo (conservação do pescado) ao longo do tempo e apenas um pequeno incremento na quantidade dos pontos de desembarque ou frigoríficos (armazenagem e distribuição do pescado) (Tabela 4). Além disso, os dados estatísticos no Brasil sobre a produção pesqueira são deficientes e até mesmo inexistentes em muitas regiões do país. Isto torna difícil um levantamento preciso sobre a produção e sobre as condições dos estoques pesqueiros explorados (GARCEZ e SANCHEZBOTERO, 2005; HAIMOVICI, 2011; FERNANDES et al., 2014). Isso pode estar relacionado à redução de estoques pesqueiros tradicionalmente capturados e a consequente exploração de outros recursos marinhos. A principal espécie alvo capturada através de redes de arrasto de fundo não somente a partir do porto de Atafona, mas em águas jurisdicionais brasileiras (MPA, 2011), é o camarão sete barbas. A produção dessa espécie de pescado está em declínio (SOUZA et al.,
2009; MPA, 2011; FERNANDES et al., 2014) e desde a década de 1970 há alertas sobre a necessidade de ações de manejo pesqueiro direcionado a esta espécie (SANTOS et al., 1973).

Segundo PIEDRAS et al. (2012), as comunidades pesqueiras que enfrentam redução dos estoques explorados tendem a utilizar redes de pesca maiores com dimensões de malha menores, intensificando o esforço de pesca para manter a viabilidade da atividade. Isso também foi verificado em Atafona e percebido pelos pescadores entrevistados que relataram o aumento no esforço de pesca e a redução dos estoques pesqueiros (Tabelas 3, 4 e 6).

A maioria dos estoques pesqueiros comerciais no Brasil e no mundo está sobreexplotada ou colapsada (CASTELLO, 2007; HAIMOVICI, 2011; KLEISNER et al., 2013). Segundo ISAC-NAHUN (2006), os estoques costeiros da região nordeste do Brasil estão em franca explotação e alguns estoques como da lagosta Panulirus sp. e do pargo Lutjanus purpureus encontram-se esgotados, fazendo que as embarcações se desloquem para a costa norte do país. HAIMOVICI (2011) afirma que muitos estoques pesqueiros da região sul e sudeste do Brasil também se encontram sobrexplotados. Este fato reduz a abundância das espécies alvo e os pescadores passam a investir em novas tecnologias e capacidade de captura para tentar manter ou até ampliar a produção (GRAÇA-LOPES et al., 2002). No entanto, o resultado da produção pesqueira pode não refletir diretamente os investimentos na atividade, como ocorre em outros setores econômicos, pois esse resultado depende do volume disponível dos estoques explorados, da sua captura efetiva e de condições ambientais favoráveis à condução da pesca (CASTRO, 2005).

No norte do Rio de Janeiro está implantado um megaempreendimento portuário (CLIPA) cuja área de influência inclui parte dos pesqueiros preferenciais dos pescadores do porto de Atafona. Os efeitos do CLIPA sobre a pesca são percebidos pelos pescadores (ZAPPES et al., 2016), e isso explica os relatos dos entrevistados no presente estudo de "alteração nos pesqueiros preferenciais" como um dos fatores que vem afetando as pescarias na região. Atividades portuárias geram impacto direto no ambiente em que estão inseridas, tais como modificações na morfologia da costa, redução ou exclusão de espécies nativas da flora e da fauna, invasão de espécies exóticas e poluição (SOUZA et al., 2009; OLIVEIRA et al., 2016; ZAPPES et al., 2016).

Além disso, segundo os autores supracitados, no entorno das atividades portuárias são definidas áreas de exclusão para a prática pesqueira que impactam diretamente a atividade. Na região estudada, as áreas de exclusão pesqueira localizadas nas 
proximidades da linha de costa incluem atualmente $128 \mathrm{~km} 2$ de águas costeiras entre $\sim 21^{\circ} 50^{\prime}$ 'S e $22^{\circ} 00^{\prime} S$ que tenderão a se ampliar a partir do incremento das operações portuárias. Desta forma, é esperado que os pescadores se afastem cada vez mais da linha de costa para captura das espécies alvo, exigindo uma frota pesqueira mais moderna e com maior autonomia de operação. Segundo os pescadores locais, embarcações de outros estados, incluindo embarcações da frota industrial, operam na região norte do Rio de Janeiro gerando conflito com a pesca local na disputa pelos pesqueiros e pelos recursos disponíveis.

\section{CONCLUSÃO}

As principais mudanças temporais ocorridas na pesca extrativa marinha praticada a partir do porto de Atafona se referem a: i) incremento da tecnologia pesqueira e da capacidade de captura das embarcações, ii) variações nas modalidades de pesca preferenciais e iii) alteração no tamanho da malha das redes de espera. O primeiro aspecto tende a aumentar a pressão sobre os recursos pesqueiros regionais. $O$ segundo caso indica que um dos mais importantes recursos pesqueiros da região, o camarão sete barbas, já poderia estar localmente sobrexplotado uma vez que houve redução no uso das redes de arrasto de fundo. Finalmente, a terceira mudança indicaria que o tamanho dos peixes capturados na região está diminuindo, o que pode colocar em risco a reposição dos estoques de muitas espécies cujas capturas ocorreriam antes que os indivíduos atingissem o tamanho de primeira maturação.

Diante do exposto, estudos e medidas de manejo pesqueiro devem ser realizados para garantir a manutenção dos estoques locais em níveis viáveis de exploração comercial, minimizando os impactos da pesca. Nesse sentido, estudos que abordem estimativas de tamanho dos estoques pesqueiros e suas características quanto ao porte dos indivíduos, período de reprodução e capacidade de reposição são importantes. Adicionalmente, o monitoramento dos desembarques pesqueiros e das modificações relacionadas à frota, incluindo dimensão das embarcações e características dos artefatos de pesca utilizados, devem ser conduzidos sistematicamente. Dessa forma, será possível avaliar a pressão que a atividade pesqueira local está exercendo sobre esses estoques.

\section{AGRADECIMENTOS}

Aos pescadores de Atafona pela atenção e colaboração para a realização do presente estudo. A técnica de campo Silvana Ribeiro Gomes pelo auxílio no levantamento das embarcações em atividade e na mobilização dos pescadores para a realização das entrevistas. A FIPERJ pela oportunidade de estágio na região concedida a B.C. Bonfim. A.P.M. Di Beneditto agradece ao CNPq (301.405/2013-1) e a FAPERJ (E$26 / 201.161 / 2014$ ) pelo fomento à pesquisa.

\section{REFERÊNCIAS}

ABDALLAH, P.R. \& CASTELLO, J.P. 2003. O momento de repensar a economia pesqueira no Brasil. Disponível em: <http://www.comciencia.br/ reportagens/litoral/lit13.shtml>. (último acesso em 22/02/20016).

BRASIL, 2009 DECRETO n. 11.959, de 29 de junho de 2009. Dispõe sobre a Política Nacional de Desenvolvimento Sustentável da Aquicultura e da Pesca, regula as atividades pesqueiras, revoga a Lei no 7.679 , de 23 de novembro de 1988, e dispositivos do Decreto-Lei no 221, de 28 de fevereiro de 1967, e dá outras providências. Diário Oficial da União, Brasília, 30 de junho de 2009, $\mathrm{n}^{\circ}$. 122, Seção 1, p. 1-3.

BRASIL, 2011 INSTRUÇÃO NORMATIVA n. 02, de 25 de janeiro de 2011. Dispõe sobre os procedimentos administrativos para a inscrição de pessoas físicas no Registro Geral da Atividade Pesqueira nas categorias de Pescador Profissional e de Aprendiz de Pesca no âmbito do MPA. Diário Oficial da União, 26 de janeiro de 2011, n. 18, Seção 1, p. 34-36.

CAPELLESSO, A.J.; CAZELLA, A.A. 2011. Pesca artesanal entre crise econômica e problemas socioambientais: estudo de caso nos municípios de Garopaba e Imbituba (SC). Ambiente \& Sociedade, 14(2): 15-33.

CASTELLO, J.P. 2007. Gestão sustentável dos recursos pesqueiros, isto é realmente possível? Pan-American Journal of Aquatic Sciences, 2(1): 47-52.

CASTRO, L. A. B. 2005. Esforço de pesca: diminuir para melhorar. Instituto de Pesca SP. Disponível em: <http://www.pesca.sp.gov.br/noticia.php?id_ not=475>. Acessado em: 06/06/16.

CLAUZET, M.; RAMIRES, M. e BARRELA, W. 2005. Pesca artesanal e o conhecimento local de duas populações caiçaras (enseada do Mar Virado e Barra do Una) no litoral de São Paulo, Brasil. Revista Multiciência, 4: 1-22.

CEPSUL - Centro de Pesquisa e Gestão de Recursos Pesqueiros do Litoral Sudeste e Sul. 2014. Disponível em: <http://www.icmbio.gov.br/cepsul/ projetos-e-atividades-40731/artes-da-pesca.html> 
Acesso em: 23/03/2014.

DI BENEDITTO, A. P. M. 2001. A pesca artesanal na costa norte do Rio de Janeiro. Bioikos, 15(2): 103-107.

DI BENEDITTO, A. P. M.; RAMOS, R. M. A.; LIMA, N. R. W. 1998. Fishing on Northern Rio de Janeiro States (BRAZIL) and relation with small cetaceans. Braz. Arch. Biol. Tech., 41(3): 296-302.

FALCÃO, H. G. 2013. Conflito, Territorialidade e Mundança: Um Estudo sobre a Dinâmica na Pesca de Atafona- São João da Barra (RJ). Dissertação, Universidade Federal Fluminense.

FAO - Food and Agriculture of the United Nations. 2016. The state of world fisheries and aquaculture. Disponível em: http://www.fao.org/3/a-i5798e.pdf Acesso em 10/08/17.

FERNANDES, L. P; KEUNECKE, K. A.; DI BENEDITTO, A. P. M. 2014. Produção e socioeconomia da pesca do camarão sete-barbas no norte do estado do Rio de Janeiro. Boletim Instituto de Pesca, 40(4): $541-555$.

FERNANDEZ, G. B.; ROCHA, T. B.; PEREIRA, T. G.; FIGUEREDO JR, A. G. 2006. Morfologia e Dinâmica da Praia entre Atafona e Grussaí, Litoral Norte do Estado do Rio de Janeiro. VI Simpósio Nacional de Geomorfologia.

FIPERJ - Fundação Instituto de Pesca do Estado do Rio de Janeiro 2015. Relatório 2015. Disponível em: <http://www.fiperj.rj.gov.br/fiperj_imagens/ arquivos/revistarelatorios2015.pdf> Acesso em: 01/08/17.

GARCEZ, D.S.; SÁNCHEZ-BOTERO, J.I. 2005. Comunidades de pescadores artesanais no estado do Rio Grande do Sul, Brasil. Atlântica, 27(1): 17-29.

GRAÇA-LOPES, R; PITA, J.B.; RODRIGUES E. S. 2002. Pesca artesanal de siris (Crustacea, Decapoda, Portunidae) na região estuarina de Santos e São Vicente (SP), Brasil. Boletim do Instituto de Pesca, 27 (1): 7 - 19.

HAIMOVICI, M. 2011. Sistemas pesqueiros marinhos e estuarinos do Brasil: caracterização e análise da sustentabilidade. Rio Grande: Ed. da FURG. 104 p.

ISAAC-NAHUM, V. J. 2006. Explotação e manejo dos recursos pesqueiros do litoral Amazônico: um desafio para o futuro. Ciência e Cultura, 58: 33-36.

KLEISNER, K.; ZELLER, D.; FROESE, R.; PAULY, D. 2013. Using global catch data for inferences on the world's marine fisheries. Fish and Fisheries, 14: 293-311.

MPA - Ministério da Pesca e Aquicultura. 2011. Boletim Estatístico da Pesca e Aquicultura Brasil 128p.

MPA - Ministério da Pesca e Aquicultura. 2014. Pesca Artesanal. Disponível em <http://www.mpa. gov.br/index.php/pesca/artesanal> Acesso em:
12/02/2016.

OLIVEIRA, P. C.; DI BENEDITTO, A. P. M. ; BULHÕES, E. M. R.; ZAPPES, C. A. 2016. Artisanal fishery versus port activity in southern Brazil. Ocean \& Coastal Management, 129: 49-57.

PIEDRAS, S. R. N.; SANTOS, J. D.; FERNANDES, J. M.; TAVARES, R. A.; SOUZA, D. M. POUEY, J. L. O. F. 2012. Caracterização da atividade pesqueira na Lagoa Mirim, Rio Grande do Sul - Brasil. Revista Brasileira de Agrociência, 18: 107-116.

SANTOS, E. P.; VALENTINI, H.; NEIVA, G. S.; MELLO, J. T. C. 1973. Curva de rendimento do camarão sete barbas, Xiphopenaeus kroyeri (Heller), da baía de Santos e adjacências. Boletim do Instituto de Pesca, 2: 67-71.

SILVA, A. P. 2014. Pesca artesanal brasileira. Aspectos conceituais, históricos, institucionais e prospectivos. Palmas: Embrapa Pesca e Aquicultura. 32p. Disponível em: http://ainfo.cnptia. embrapa.br/digital/bitstream/item/108691/1/bpd3. pdf Acesso em: 01/08/2017.

SOUZA, T.; OLIVEIRA, V. P. 2010. Conflito socioambiental entre atividades de pesca artesanal marinha e implantação de atividades portuárias no Norte Fluminense. Boletim do Observatório Ambiental Alberto Ribeiro Lamego, 4(2): 219-229.

SOUZA, K. M.; CASARINI, L. M.; HENRIQUES, M. B.; ARFELLI, C. A.; GRAÇA-LOPES, R. 2009. Viabilidade econômica da pesca de camarão-setebarbas com embarcação de pequeno porte na praia do Perequê, Guarujá, estado de São Paulo. Informações Econômicas, 39(4): 577-586.

ZAPPES, C. A.; OLIVEIRA, P. C.; DI BENEDITTO, A. P. M. 2016. Percepção de pescadores do Norte Fluminense sobre a viabilidade da pesca artesanal com a implantação de megaempreendimento portuário. Boletim do Instituto de Pesca, 42(1): 73-88.

Submetido: Março/2017 Revisado: Agosto/2017 Aceito: Agosto/2017 